\title{
Comparative Study of the Corrosion Inhibition and Adsorption of Ripe and Unripe Plantain (Musa paradisiaca) Peel Extract on Zinc in 2.0M $\mathrm{CH}_{3} \mathrm{COOH}$ Acid Solution
}

\author{
Osaribie, N.A. ${ }^{1}$, William-Ebi, D. ${ }^{2}$ and Tombiri, M.Z. ${ }^{3}$ \\ ${ }^{1-3}$ Department of Chemical Engineering \\ Faculty of Engineering, Niger Delta University \\ Wilberforce Island, Bayelsa State
}

Nigeria

\begin{abstract}
The aim of this study was to investigate the corrosion inhibition and adsorption of both ripe and unripe Musa paradisiaca peel on zinc sheet in 2.0M $\mathrm{CH}_{3} \mathrm{COOH}$ acid solution. The corrosion inhibition study was carried out using weight loss study at temperatures of $303 \mathrm{~K}, 313 \mathrm{~K}$ and $323 \mathrm{~K}$. Comparatively the peel extract of the ripe Musa paradisiaca showed higher inhibition efficiency to corrosion than the unripe with tannins as the main difference in the constituents which has higher concentration of tannin in the ripe and very minute in the unripe. The inhibition efficiency of the both extracts was found to decrease with rise in temperature. The experimental data complied to the Henry, Flory-Huggins and Adejo-Ekwenchi isotherms amongst which the Henry Isotherm gave the best fit having the highest regression $\left(R^{2}\right)$ values for both the ripe and unripe. The positive values of $\Delta H_{a d s}$ and negative values $\Delta G_{\text {ads }}$ revealed the endothermic nature and spontaneity of the adsorption process respectively. Through the Kinetic-thermodynamic parameters such as $E_{a,}, \Delta H_{a d s,}, \Delta S_{a d s,} \Delta G_{a d s}$ and the b parameter of the Adejo-Ekwenchi isotherm, the mechanism of adsorption was physiosorption.
\end{abstract}

Key Words: Zinc, Corrosion, Musa paradisiaca, Adsorption Isotherm, Ethanoic acid.

\subsection{INTRODUCTION}

Corrosion is the deterioration of metals in chemicals or reaction with its environment [6]. It is a ubiquitous phenomenon that deteriorates all materials, metals, plastics, glass and even concrete surfaces. Corrosion of metals can be considered as extractive metallurgy as it removes valuable metals from alloys. The study of zinc is a matter of tremendous theoretical and practical concern as it is widely used as an alloy to form important materials used in automobiles, electric components and household fixtures. Zinc as one of the most important nonferrous metals that has its extensive use in metallic coatings is amphoteric in its behavior towards acids and alkalis [7]. Zinc and zinc-coated products corrode rapidly in moist atmospheres forming white corrosion product-white rust.

Several inhibition methods for controlling corrosion attack has been reported and the use of inhibitors has proven to be effective and excellent in corrosion prevention. As a result of the toxicity, environmental restrictions and high cost of some inorganic inhibitors, the use of green inhibitors is being recently studied and a possible replacement of inorganic inhibitors. Organic compounds contain hetero atoms such as $\mathrm{N}, \mathrm{S}, \mathrm{O}$, polar groups $\pi$ electrons have been found to be very effective in inhibiting metallic corrosion when adsorbed on metallic surfaces [5]. This present study investigates the inhibiting, adsorption and thermodynamics of ripe and unripe Musa paradisiaca extract on zinc sheet corrosion in $2.0 \mathrm{M} \mathrm{CH}_{3} \mathrm{COOH}$ acid solution using weight loss measurement at $303 \mathrm{~K}, 313 \mathrm{~K}$ and $323 \mathrm{~K}$. 
International Journal of Advances in Scientific Research and Engineering (ijasre), Vol 5 (7), July-2019

\subsection{MATERIALS AND METHODS}

\subsection{Specimen Preparation}

Rectangular pure zinc strips were used with dimension $80 \mathrm{~mm} \times 60 \mathrm{~mm} \times 0.5 \mathrm{~mm}$. The specimens were polished with emery paper, washed with deionized water, dried and weighed with an electronic balance to obtain their initial weights.

\subsection{Preparation of extract}

Fresh peels of ripe and unripe Musa paradisiaca were collected, washed, dried and pulverized into powdering form. The powdered extracts were Soxhlet extracted using ethanol and separated in a rotary evaporator at $80^{\circ} \mathrm{C}$ to obtain a solution free of ethanol. An aqueous aggressive solution of 2.0M Ethanoic acid was prepared. The stock solution was diluted with appropriate quantity of 2.0M Ethanoic acid to obtain inhibitor test solutions of $0.1-0.5 \mathrm{~g} / \mathrm{l}$ concentrations.

\subsection{Weight loss test}

Weight loss measurements was carried out on zinc strips at different temperatures of 303K, 313K and 323K. The dried samples were weighed and recorded before immersion into their respective solutions. The weight loss of the specimens was recorded every 5 days for a period of 30 days. The corrosion rate, percentage inhibition efficiency and degree of surface coverage $(\theta)$ was calculated using the equations below:

$$
\text { C.R }=\frac{87.6 \mathrm{~W}}{\rho A T}
$$

Where $\mathrm{W}$ is weight loss of zinc sheet $(\mathrm{g}), \mathrm{A}$ is the total surface area of specimen in $\left(\mathrm{cm}^{2}\right)$, $\mathrm{t}$ is the exposure time in hours(hr) and $\rho$ is specimen's density $\left(\mathrm{g} / \mathrm{cm}^{3}\right)$.

$\eta \%=\frac{\mathrm{CR}_{0}-\mathrm{CR}}{\mathrm{CR}_{0}} \times 100 \%$

where $\mathrm{CR}_{0}$ and $\mathrm{CR}$ are the corrosion rates in $(\mathrm{mm} / \mathrm{yr})$ without and with different inhibitor concentrations.

$\theta=\frac{\mathrm{CR}_{0}-\mathrm{CR}}{\mathrm{CR}_{0}}$

\subsection{RESULTS AND DISCUSSION}

\subsection{Phytochemical Analysis}

Table 1: Phytochemical Composition of Ethanol extract of Musa paradisiaca peel

\begin{tabular}{llc}
\hline Phytochemical Constituents & $\begin{array}{l}\% \text { Composition of unripe } \\
\text { peel }\end{array}$ & Composition of ripe peel \\
Alkaloids & $1.26 \pm 0.051$ & $1.37 \pm 0.048$ \\
Tannins & $0.001 \pm 0.005$ & $1.577 \pm 0.004$ \\
Saponins & $1.547 \pm 0.0042$ & $1.827 \pm 0.0042$ \\
Flavonoids & $1.321 \pm 0.003$ & $0.981 \pm 0.0014$ \\
Glycosides & $0.623 \pm 0.002$ & $0.351 \pm 0.001$
\end{tabular}

The results from Table 1 clearly reveals the phytochemical constituents present in the inhibitor acting as anti-corrosion agents are higher in concentrations in the ripe Musa paradisiaca. 
International Journal of Advances in Scientific Research and Engineering (ijasre), Vol 5 (7), July-2019

\section{$3.2 \mathrm{pH}$ Measurement}

The $\mathrm{pH}$ values of the $2.0 \mathrm{M}$ ethanoic acid, the ripe and unripe musa paradisiaca peel extract are shown in the table below:

Table 2. pH values of the $2.0 \mathrm{M}$ ethanoic acid, the ripe and unripe musa paradisiaca peel extract

\begin{tabular}{lcc}
\hline Solvent & $\mathrm{pH}$ Value & Nature \\
\hline Ethanoic Acid & 2.6 & Acidic \\
Unripe Peel Extract & 6.2 & Acidic \\
Ripe Peel Extract & 6.3 & Acidic \\
\hline
\end{tabular}

\subsection{Weight loss}

\subsubsection{Effect of temperature on Corrosion rate}

Table 3 and 4 shows calculated values of corrosion rates without and with inhibitor concentrations at different temperatures. It was observed that the corrosion rate decreases as the inhibitor concentration increases for both extracts. As the temperature increases, corrosion rate increases which is more pronounced in the unripe extract solution. This is because the ripe extract solution has a higher percentage of the phytochemical constituents thereby having a lower corrosion rate.

\subsubsection{Effect of temperature on Inhibition efficiency}

The results obtained from table 3 and 4 showed that increase in inhibitor concentration increases the efficiency of the both extracts. Increase in inhibitor concentration in the acidic medium resulted to adsorption of more active ions from the extracts on the surface of zinc strips and less contact of the zinc strips with the acidic environment, thereby increasing the inhibitor efficiencies. This supports the results obtained by [1]. From figure 1 and 2, it was observed that as temperature increases, the inhibition efficiencies of the ripe and unripe Musa paradisiaca extracts decreased, a trend often attributed to physical adsorption and vice versa for chemisorption [3]. Thus as temperature increases, the number of adsorbed molecules becomes less stable and decreases, leading to a decrease in the inhibition efficiency.

Table 3. Corrosion rate, Inhibition efficiency and Surface coverage of Unripe Musa paradisiaca at different temperatures

\begin{tabular}{|c|c|c|c|c|c|c|c|c|c|}
\hline \multicolumn{4}{|c|}{$303 \mathrm{~K}$} & \multicolumn{3}{|c|}{$313 \mathrm{~K}$} & \multicolumn{3}{|c|}{$323 \mathrm{~K}$} \\
\hline $\begin{array}{l}\text { Conc } \\
(\mathrm{g} / 1)\end{array}$ & $\begin{array}{l}\mathrm{CR} \times 10^{-3} \\
(\mathrm{~mm} / \mathrm{yr})\end{array}$ & $\eta \%$ & $\theta$ & $\begin{array}{l}\mathrm{CR} \times 10^{-3} \\
(\mathrm{~mm} / \mathrm{yr})\end{array}$ & $\eta \%$ & $\theta$ & $\begin{array}{l}\mathrm{CR} \times 10^{-3} \\
(\mathrm{~mm} / \mathrm{yr})\end{array}$ & $\eta \%$ & $\Theta$ \\
\hline Blank & 0.802 & - & - & 1.268 & - & - & 1.484 & - & - \\
\hline 0.1 & 0.343 & 57.23 & 0.572 & 0.573 & 54.81 & 0.548 & 0.722 & 51.35 & 0.514 \\
\hline 0.2 & 0.287 & 64.21 & 0.642 & 0.487 & 61.59 & 0.616 & 0.610 & 58.89 & 0.589 \\
\hline 0.3 & 0.230 & 71.32 & 0.713 & 0.403 & 68.22 & 0.682 & 0.519 & 65.03 & 0.650 \\
\hline 0.4 & 0.172 & 78.55 & 0.786 & 0.315 & 75.16 & 0.752 & 0.408 & 72.51 & 0.725 \\
\hline 0.5 & 0.114 & 85.79 & 0.858 & 0.226 & 82.18 & 0.822 & 0.300 & 79.78 & 0.798 \\
\hline
\end{tabular}


International Journal of Advances in Scientific Research and Engineering (ijasre), Vol 5 (7), July-2019

Table 4. Corrosion rate, Inhibition efficiency and Surface coverage of Ripe Musa paradisiaca at different temperatures

\begin{tabular}{|c|c|c|c|c|c|c|c|c|c|}
\hline \multirow[b]{2}{*}{$\begin{array}{l}\text { Conc } \\
(\mathrm{g} / 1)\end{array}$} & \multicolumn{3}{|c|}{$303 \mathrm{~K}$} & \multicolumn{3}{|c|}{$313 \mathrm{~K}$} & \multicolumn{3}{|c|}{$323 \mathrm{~K}$} \\
\hline & $\begin{array}{l}\mathrm{CR} \times 10^{-3} \\
(\mathrm{~mm} / \mathrm{yr})\end{array}$ & $\eta \%$ & $\theta$ & $\begin{array}{l}\mathrm{CR} \times 10^{-3} \\
(\mathrm{~mm} / \mathrm{yr})\end{array}$ & $\eta \%$ & $\Theta$ & $\begin{array}{l}\mathrm{CR} \times 10^{-3} \\
(\mathrm{~mm} / \mathrm{yr})\end{array}$ & $\eta \%$ & $\theta$ \\
\hline Blank & 0.687 & - & - & 1.065 & - & - & 1.324 & - & - \\
\hline 0.1 & 0.245 & 64.29 & 0.643 & 0.422 & 60.38 & 0.604 & 0.585 & 55.81 & 0.558 \\
\hline 0.2 & 0.198 & 71.18 & 0.712 & 0.373 & 64.98 & 0.650 & 0.529 & 60.05 & 0.601 \\
\hline 0.3 & 0.147 & 78.60 & 0.786 & 0.298 & 72.02 & 0.720 & 0.440 & 66.77 & 0.668 \\
\hline 0.4 & 0.102 & 85.15 & 0.852 & 0.203 & 80.94 & 0.809 & 0.321 & 75.76 & 0.758 \\
\hline 0.5 & 0.049 & 92.87 & 0.929 & 0.133 & 87.51 & 0.875 & 0.208 & 84.29 & 0.843 \\
\hline
\end{tabular}

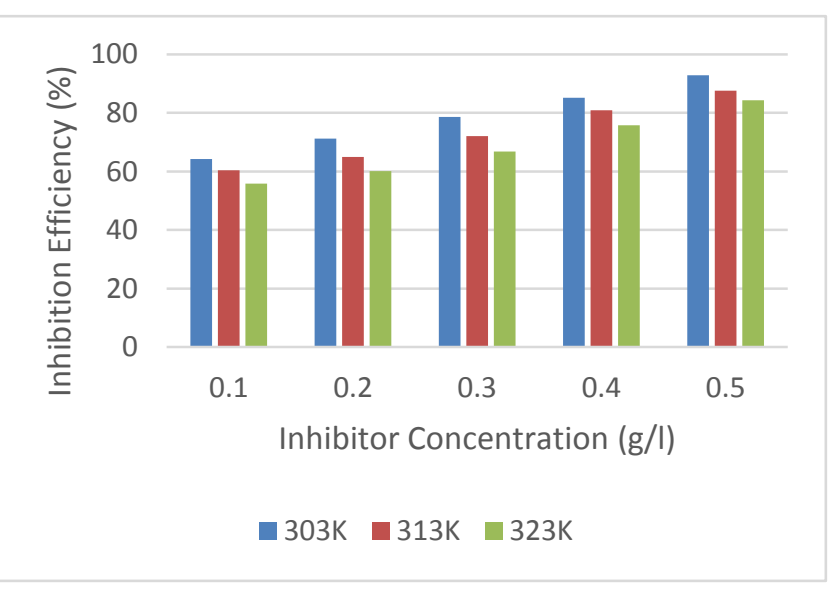

Fig 1. Inhibition efficiency vs Inhibitor concentration for Ripe Musa paradisiaca

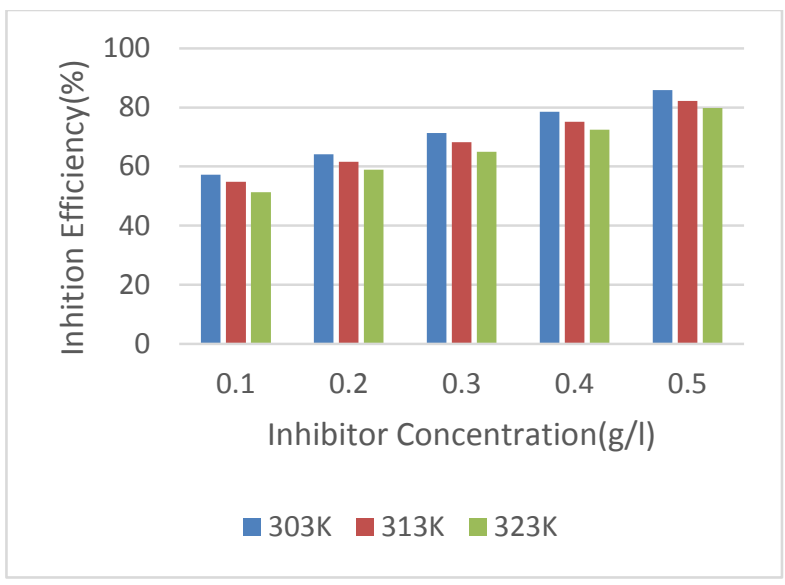

Fig 2. Inhibition efficiency vs Inhibitor concentration for Unripe Musa paradisiaca

\subsection{Kinetics and Thermodynamic Model}

The activation energy at different concentrations of ripe and unripe Musa paradisiaca extracts in $2.0 \mathrm{M}$ ethanoic medium was calculated by plotting Log CR against $\frac{1}{\mathrm{~T}}$ which gave linear graphs with slope equal to $=\frac{-\mathrm{E}_{\mathrm{a}}}{2.303 \mathrm{R}}$ and intercept equal to LogA using The Arrhenius type equation [4].

$\log C R=\frac{-E_{a}}{2.303 R T}+\log A$

Where $\mathrm{CR}$ is the corrosion rate. $\mathrm{E}_{\mathrm{a}}$ is the apparent activation energy $(\mathrm{KJ} / \mathrm{mol}), \mathrm{T}$ is absolute temperature $(\mathrm{K}), \mathrm{R}$ is the universal gas constant $(8.314 \mathrm{~J} / \mathrm{MolK})$ and $\mathrm{A}$ is the pre exponential factor. 
International Journal of Advances in Scientific Research and Engineering (ijasre), Vol 5 (7), July-2019

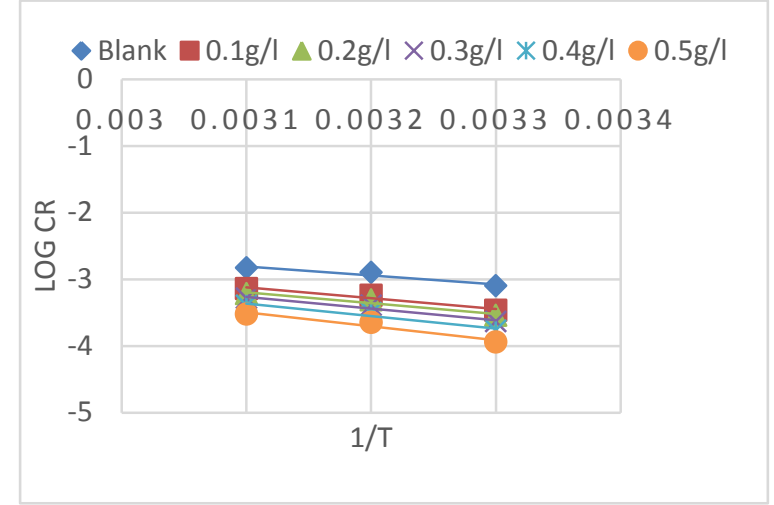

Fig 3: Variation of $\log C R$ against $\left(\frac{1}{T}\right)$ for Unripe Musa paradisiaca extract

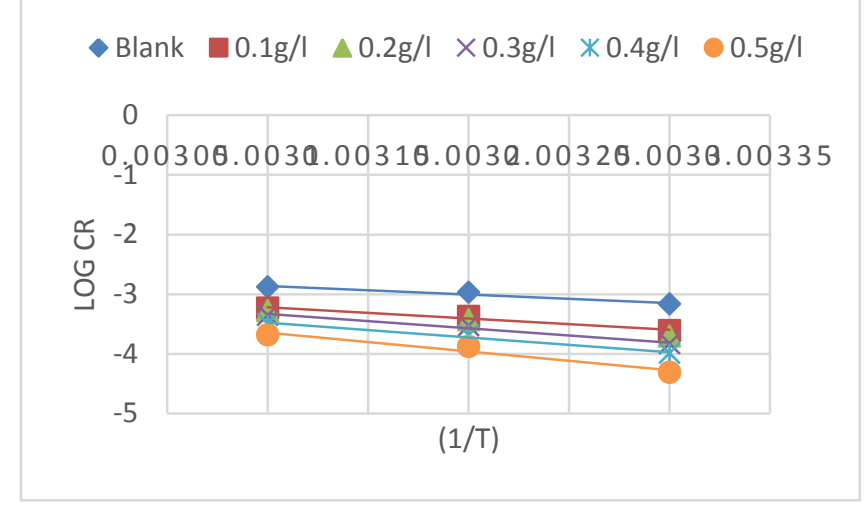

Fig 4: Variation of $\log$ CR against $\left(\frac{1}{T}\right)$ for Ripe Musa paradisiaca extract

The apparent activation energies for the both unripe and ripe extracts were calculated from the Arrhenius plots in Fig 3 and 4 respectively. The values of $\mathrm{E}_{\mathrm{a}}$ as recorded in Table 5 was found to increase as the inhibitor concentration increases and higher than that of the blank indicating that the inhibitors inhibited the corrosion rate in the acidic media. Higher values of $E_{a}$ in the presence of the inhibitors increases the energy barrier which decelerates the rate of corrosion on the zinc surface. The $\mathrm{E}_{\mathrm{a}}$ values ranges from $25.19 \mathrm{KJ} / \mathrm{mol}$ to $40.23 \mathrm{KJ} / \mathrm{mol}$ (unripe) and $27.28 \mathrm{KJ} / \mathrm{mol}$ to $60.10 \mathrm{KJ} / \mathrm{mol}$ (ripe). The range of values of $\mathrm{E}_{\mathrm{a}}$ are below the threshold value of $80 \mathrm{KJ} / \mathrm{mol}$ which satisfies the trend for physisorption [9].

Table 5. Calculated values of corrosion kinetic and thermodynamic parameters for the corrosion of Zinc in $2.0 \mathrm{M}$ $\mathrm{CH}_{3} \mathrm{COOH}$ without and with various concentrations of unripe and ripe Musa parasidiaca extract.

\begin{tabular}{|c|c|c|c|c|c|c|c|c|}
\hline & Unripe $M u$ & a paradisi & & & Ripe Musa & paradisiac & & \\
\hline $\begin{array}{l}\text { Conc } \\
(\mathrm{g} / 1)\end{array}$ & $\begin{array}{l}\mathrm{A} \times 10^{2} \\
\left(\mathrm{~g} / \mathrm{cm}^{2} \mathrm{hr}\right)\end{array}$ & $\begin{array}{c}\mathrm{E}_{\mathrm{a}} \\
(\mathrm{KJ} / \mathrm{mol})\end{array}$ & $\begin{array}{c}\Delta H_{\text {ads }} \\
(\mathrm{KJ} / \mathrm{mol})\end{array}$ & $\begin{array}{r}\Delta S_{\text {ads }} \\
(\mathrm{J} / \mathrm{mol})\end{array}$ & $\begin{array}{l}\mathrm{A} \times 10^{2} \\
\left(\mathrm{~g} / \mathrm{cm}^{2} \mathrm{hr}\right)\end{array}$ & $\begin{array}{c}\mathrm{E}_{\mathrm{a}} \\
(\mathrm{KJ} / \mathrm{mol})\end{array}$ & $\begin{array}{l}\Delta H_{\text {ads }} \\
(\mathrm{KJ} / \mathrm{mol})\end{array}$ & $\begin{array}{l}\Delta \mathrm{S}_{\mathrm{ads}} \\
(\mathrm{J} / \mathrm{mol})\end{array}$ \\
\hline Blank & 0.18 & 25.19 & 22.93 & -228.28 & 0.36 & 27.28 & 24.62 & -204.09 \\
\hline 0.1 & 0.77 & 30.94 & 28. & -217.71 & 4.38 & 36.19 & 33.53 & -203.26 \\
\hline 0.2 & 0.77 & 31.34 & 28.68 & -217.81 & 22.88 & 40.86 & 38.21 & -189.52 \\
\hline 0.3 & 1.65 & 33.84 & 31.17 & -211.43 & 111.56 & 45.59 & 42.92 & -176.40 \\
\hline 0.4 & 2.83 & 35.92 & 33.26 & -206.93 & 174.02 & 47.66 & 45.01 & -172.68 \\
\hline 0.5 & 10.45 & 40.23 & 37.57 & -196.06 & 12316.86 & 60.10 & 57.45 & -137.26 \\
\hline
\end{tabular}

$\rightarrow$ Blank $\square 0.1 \mathrm{~g} / \mathrm{l} \quad 0.2 \mathrm{~g} / \mathrm{l} \times 0.3 \mathrm{~g} / \mathrm{l} * 0.4 \mathrm{~g} / \mathrm{l} \quad 0.5 \mathrm{~g} / \mathrm{l}$

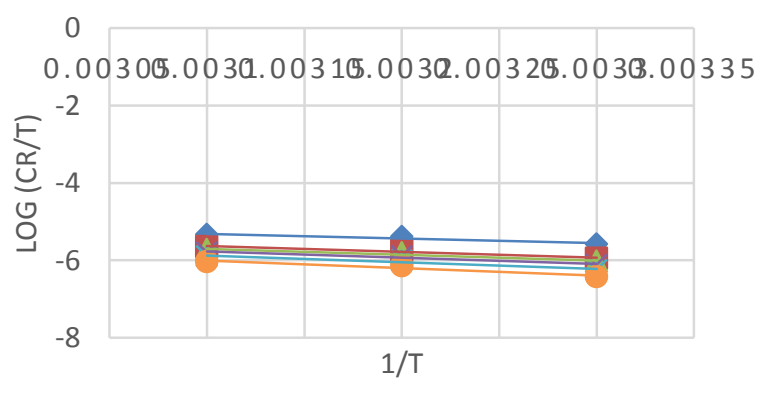

Fig 5. Variation of $\log \left(\frac{\mathrm{CR}}{\mathrm{T}}\right)$ against $\left(\frac{1}{\mathrm{~T}}\right)$ for paradisiaca Ripe Musa paradisiaca

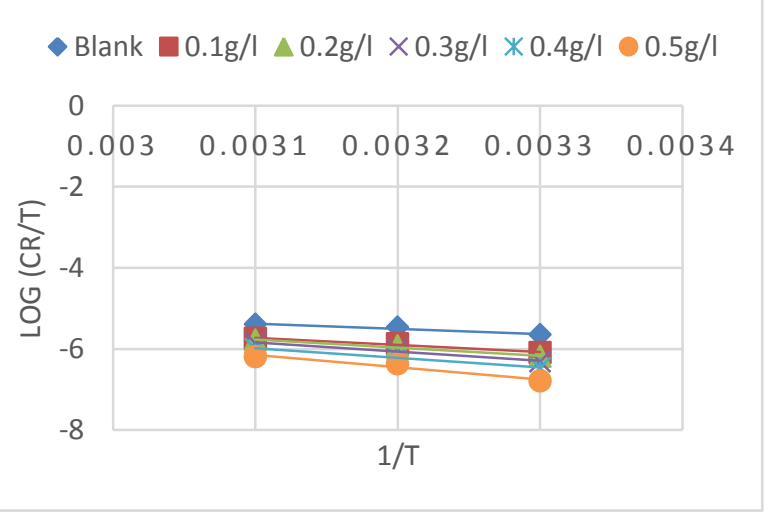

Fig 6. Variation of $\log \left(\frac{\mathrm{CR}}{\mathrm{T}}\right)$ against $\left(\frac{1}{\mathrm{~T}}\right)$ for Unripe Musa 
Thermodynamic parameters such as the Enthalpy $\left(\Delta \mathrm{H}_{\mathrm{ads}}\right)$ and Entropy $\left(\Delta \mathrm{S}_{\mathrm{ads}}\right)$ were calculated using the Eyring transition state equation shown below:

$$
\log \left(\frac{\mathrm{CR}}{\mathrm{T}}\right)=\log \left(\frac{\mathrm{R}}{\mathrm{Nh}}\right)+\frac{\Delta \mathrm{S}_{\mathrm{ads}}}{2.303 \mathrm{R}}-\frac{\Delta \mathrm{H}_{\mathrm{ads}}}{2.303 \mathrm{RT}}
$$

Where $\mathrm{N}$ is the Avogadro's number $\left(6.2252 \times 10^{23}\right)$ and $\mathrm{h}$ is the Planck's constant $\left(6.6262 \times 10^{-34} \mathrm{Js}\right)$

Fig 5 and 6 shows the plot of $\log \left(\frac{\mathrm{CR}}{\mathrm{T}}\right)$ against $\frac{1}{\mathrm{~T}}$ for both ripe and unripe Musa paradisiaca extract gave linear graphs with slope equal to $-\frac{\Delta \mathrm{H}_{\mathrm{ads}}}{2.303 \mathrm{RT}}$ and intercept equal to $\log \left(\frac{\mathrm{R}}{\mathrm{Nh}}\right)+\frac{\Delta \mathrm{S}_{\mathrm{ads}}}{2.303 \mathrm{R}}$. From Table 5 , the positive values of the enthalpy of adsorption depicts the endothermic nature of the adsorption process. The large negative values of the entropy of adsorption indicates that the activated complex in the rate-determining step represents association rather than dissociation implying that disorderliness decreases ongoing from the reactants to the activated complex [8]. The results obtained is also in agreement with [2].

\subsection{Adsorption Considerations}

Adsorption isotherms play an important role in describing the adsorption behavior and nature of interactions of the extracts on metallic surfaces. The adsorption behavior of Ethanolic extract of both ripe and unripe Musa paradisiaca was studied by fitting the experimental data into Henry, Flory-Huggins and Adejo-Ekwenchi isotherms. The linearized forms for Henry, Flory-Huggins and Adejo-Ekwenchi isotherms are given by equation 6,7 and 8 respectively.

$$
\begin{aligned}
& \log \theta=\log K_{a d s}+\log C \\
& \log \left(\frac{\theta}{C}\right)=\log K_{a d s}+x \log (1-\theta) \\
& \log \left(\frac{1}{1-\theta}\right)=\log K_{a d s}+b \log C
\end{aligned}
$$

Where $\mathrm{x}$ describes the number of molecules of the inhibitor adsorbed, $\mathrm{b}$ describes the mode of adsorption and $\mathrm{K}_{\mathrm{ads}}$ represents the adsorption constant which is used to calculate the Gibbs free energy of adsorption from equation 9

$$
\Delta \mathrm{G}_{\mathrm{ads}}=-2.303 \mathrm{RTLog}\left(55.5 \mathrm{~K}_{\mathrm{ads}}\right)
$$


International Journal of Advances in Scientific Research and Engineering (ijasre), Vol 5 (7), July-2019

Table 6. Parameters of various Adsorption Isotherms for Adsorption of Ethanolic extract of Unripe Musa paradisiaca on zinc surface

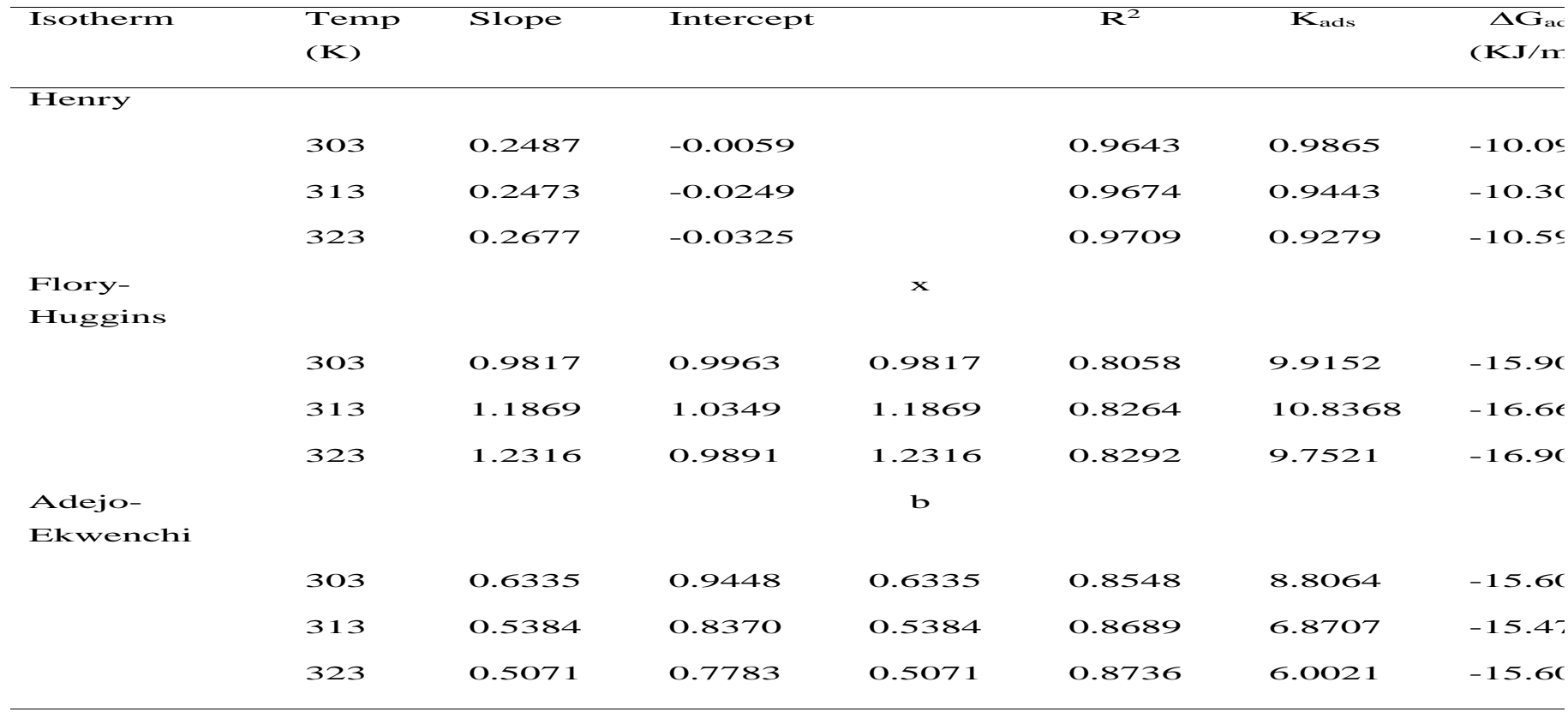

Table 7. Parameters of various Adsorption Isotherms for Adsorption of Ethanolic extract of Ripe Musa paradisiaca on zinc surface

\begin{tabular}{|c|c|c|c|c|c|c|c|}
\hline Isotherm & $\begin{array}{l}\text { Temp } \\
(\mathrm{K})\end{array}$ & Slope & Intercept & & $\mathbf{R}^{2}$ & $\mathbf{K}_{\text {ads }}$ & $\begin{array}{c}\Delta \mathrm{G}_{\mathrm{ads}} \\
(\mathrm{KJ} / \mathrm{mol})\end{array}$ \\
\hline \multicolumn{8}{|l|}{ Henry } \\
\hline & 303 & 0.2240 & 0.0216 & & 0.9656 & 1.0510 & -10.24 \\
\hline & 313 & 0.2310 & -0.0048 & & 0.9261 & 0.9890 & -10.42 \\
\hline & 323 & 0.2512 & -0.0223 & & 0.9056 & 0.9499 & -10.65 \\
\hline \multirow{2}{*}{\multicolumn{8}{|c|}{$\begin{array}{l}\text { Flory- } \\
\text { Huggins }\end{array}$}} \\
\hline & & & & & & & \\
\hline & 303 & 0.6786 & 0.9679 & 0.6786 & 0.7581 & 9.2875 & -15.74 \\
\hline & 313 & 0.8967 & 0.9886 & 0.8967 & 0.7458 & 9.7409 & -16.38 \\
\hline & 323 & 0.9491 & 0.9184 & 0.9491 & 0.6929 & 8.2871 & -16.48 \\
\hline \multirow{5}{*}{$\begin{array}{l}\text { Adejo- } \\
\text { Ekwenchi }\end{array}$} & & & & b & & & \\
\hline & & & & & & & \\
\hline & 303 & 0.8927 & 1.2479 & 0.8927 & 0.8015 & 17.6970 & -17.36 \\
\hline & 313 & 0.6702 & 0.9984 & 0.6702 & 0.813 & 9.9632 & -16.44 \\
\hline & 323 & 0.5851 & 0.872 & 0.5851 & 0.7846 & 7.4473 & -16.18 \\
\hline
\end{tabular}

The regression value $\left(\mathrm{R}^{2}\right)$ obtained from the Henry's plot as recorded in table $6 \& 7$ were close to unity which was higher in the unripe extract showing that the sorption data followed Henry isotherm.

The parameter $\mathrm{x}$ of the Flory-Huggins isotherm describes the number of active sites occupied by one inhibitor molecule [10] adsorbed and has been shown from Table 7 for Ripe Musa paradisiaca to have values less than one indicating that more than one molecules of the inhibitor occupied one active site during the inhibition process. This is unlike the case of the unripe Musa 
paradisiaca extract having the x parameter to be less than one only at $303 \mathrm{~K}$. It shows that the Flory-Huggins model was more consistent with the ripe extract than the Unripe extract, therefore the unripe extract does not really fit into the model.

The Adejo-Ekwenchi isotherm model was used as a major determinant in describing the mode of adsorption from the calculated values of the $b$ parameter. Decrease in the value of $b$ with rise in temperature signifies physiosorption while increase or fairly constant value of $\mathrm{b}$ signifies chemisorption [10]. From Tables $6 \& 7$, the calculated values of the $\mathrm{b}$ parameter for the both extracts decreased with rise in temperature, clearly showing that the adsorption of ripe and unripe Musa paradisiaca extract onto the zinc surface was physiosorption.

The values of $\Delta \mathrm{G}_{\mathrm{ads}}$ calculated from the isotherm plots were all negative which showed the spontaneity of the adsorption process. Also the values of $\Delta \mathrm{G}_{\mathrm{ads}}$ were all found to be less than $-20 \mathrm{KJ} / \mathrm{mol}$, a trend attributed to physiosorption.

\subsection{CONCLUSION}

Results from the present work shows that, ripe and unripe Musa paradisiaca extract were good corrosion inhibitors, with the ripe Musa pardisiaca extract giving the best inhibition efficiency over the unripe. The adsorption of the both extracts on zinc surface obeyed Henry, Flory-Huggins and Adejo-Ekwenchi Isotherms. The Henry isotherm gave the best fit having its regression values $\left(\mathrm{R}^{2}\right)$ for both extracts very close to unity compared to the Flory-Huggins and Adejo-Ekwenchi isotherms. The mechanism of physiosorption was proposed majorly from the b parameter of the Adejo-Ekwenchi isotherm, as well as from the calculated values $\Delta \mathrm{G}_{\mathrm{ads}}, \Delta \mathrm{H}_{\mathrm{ads}}$ and the trend of inhibition efficiency with temperature. The positive values of the enthalpy of adsorption revealed that the inhibition is endothermic in nature accompanied by an increase in entropy.

\section{REFERENCES}

[1] A. Adesanmi (2015)." Investigation of corrosion inhibition of Guava, Banana and Almond plant extract in $0.5 \mathrm{M}$ of $\mathrm{HCl}$ and $\mathrm{H}_{2} \mathrm{SO}_{4}$ Solution on Low Carbon Steel”. M.Sc Thesis Department of Mechanical Engineering, ABU, Zaria-Nigeria.

[2] F. E. Abeng, V. D. Idim, O. E. Obono, and T. O. Magu (2017). “Adsorption and adsorption isotherm: application to corrosion inhibition studies of mild steel in 2M HCl”. World Scientific News, 77(2): 298-313.

[3]A. L. Nnanna, I. O. Owate, O. C. Nwadiuko, N. D. Ekekwe, and W. J. Oji (2013).” Adsorption and Corrosion Inhibition of Gnetum Africana Leaves Extract on Carbon Steel. International Journal of Materials and Chemistry, 3(1): 10-16.

[4] N. I. Kairi and J. Kassim, (2013)." The Effect of Temperature on the Corrosion Inhibition of Mild Steel in 1M HCl Solution by Curcuma longa Extract”. Int. J. Electrochem. Sci 8, 7138-7155.

[5] P. M. Dass, A. I. Onen, O. N. Maitera, and G. Ushahemba (2015).” Corrosion Inhibition of zinc in acid medium by Moringa oleifera and Mangifera indica leaves extracts". International Journal of Development and Sustainability, 4(9): 940-950.

[6]B.E.A. Rani, and B.B.J. Basu, (2012).” Green Inhibitors for corrosion protection of metals and alloys: An Overview”. International Journal of Corrosion, pp. 1-15.

[7] R. A. P., T. V. V., \& B. M. P. (2012). Electrochemical Study of the Corrosion Behavior of Zinc Surface Treated with a New Organic Chelating Inhibitor. ISRN Metallurgy, 940107:7.

[8] S. B. Ulaeto, U. J. Ekpe, M. A. Chidiebere, and E. E. Oguzie (2012).” Corrosion Inhibition of Mild Steel in Hydrochloric Acid by Acid Extracts of Elchhornia crassipes”. International Journal of Materials and Chemistry, 2(4): 158-164.

[9] S. Manimegalai and P. Manjula (2015)." Thermodynamic and Adsorption studies for corrosion inhibition of mild steel in Aqueous Media by Sargasm swartzii (Brown algae)". J. Mater. Environ. Sci., 6(6): 1629-1637

[10] S. O. Adejo, M. M. Ekwenchi, J. A. Gbertyo, T. Menenge, and J. O. Ogbodo (2014).” Determination of Adsorption Isotherm model best fit for methanol leaf extract of Securinega virosa as corrosion inhibitor for corrosion of mild steel in HCl". Journal of advances in chemistry, 10(5): 2737-2742. 